Available online on 15.01 .2020 at http://jddtonline.info
Open Access to Pharmaceutical and Medical Research
unrestricted non-commercial use, provided the original work is properly cited

Open ${ }_{\text {Access }}$

Review Article

\title{
Targeted Based Drug Delivery System for Colon Cancer
}

\author{
Veerpal Kaur ${ }^{1}$, Amandeep Singh ${ }^{1,2}$, Kirandeep Kaur ${ }^{1}$, Goutam Rath ${ }^{3 *}$ \\ ${ }^{1}$ Department of Pharmaceutics, ISF College of Pharmacy, Moga-142001, Punjab, India \\ 2 Department of Pharmaceutical Sciences and Technology, Maharaja Ranjit Singh Punjab Technical University, Bathinda- 151001, Punjab, India \\ ${ }^{3}$ Department of Pharmaceutics, School of Pharmaceutical Sciences, Siksha O Anusandhan (Deemed to be University), Bhubaneswar-751003, \\ Odisha, India
}

\begin{abstract}
Regardless of so many advancements in the treatment, colon cancer still stands third in cancer-related deaths worldwide. Toxicity associated with conventional drugs is one of the major problems associated with chemotherapy. Targeted delivery works by concentrating the medication in the tissues of interest and reducing the concentration in remaining tissues. This delivery system helps the drug molecule to reach preferably to the desired site. The targeting will lower the requirement of a higher dose of the drug thus reducing the dosage frequency. The present review focuses on the various parameters of targeted drug delivery including the criteria for selection of drug and factors affecting the targeted drug delivery and also includes the brief discussion about different targeted drug deliveries for colon cancer therapies.
\end{abstract}

Keywords: colon cancer, targeted drug delivery, chemotherapies

Article Info: Received 10 Nov 2019; Review Completed 18 Dec 2019; $\quad$ Accepted 22 Dec 2019; Available online 15 Jan 2020

Cite this article as:

Kaur V, Singh A, Kaur A, Rath G, Targeted Based Drug Delivery System for Colon Cancer, Journal of Drug Delivery and Therapeutics. 2020; 10(1):111-122 http://dx.doi.org/10.22270/jddt.v10i1.3831

*Address for Correspondence:

Dr. Goutam Rath, Professor, Department of Pharmaceutics School of Pharmaceutical Sciences, Siksha O Anusandhan (Deemed to be University), Bhubaneswar-751003, Odisha, India

\subsection{INTRODUCTION}

The foundation of the word 'cancer' is attributed to 'Hippocrates' (460-370 B.C.), who is said to be the "Father of Medicine". Hippocrates reported various types of cancer, mentioning them by the word karkinos (carcinos), it is the Greek expression for crab or crayfish [1,2]. Cancer is a ubiquitous disease that is said to be associated with excessive mortality cases despite ongoing research. An estimated 6.35 million new cases of cancer are diagnosed worldwide annually, half of which originates in developing nations [3]. Survey of 1998 showed that in India a number of cancer patients are about 0.609 million out of which around 0.315 million are male and 0.294 million are female [4]. Cancer is said to be the second major reason for death in the world after cardiovascular diseases. Uncontrolled growth of cells indicates cancer, resulting in a primary tumor that invades and destroys other tissues. It is specified by loss of regulatory mechanism which controls cell development and maturation required for homeostasis in complex multicellular organisms. Normal cells increase their number by multiplication when there is body's requirement and dies when the requirement is over [5]. Cancer is generated when normal cells in a particular region of the body start to grow without any control. The multiplication of cells is controlled with care and help in the certain requirements of the body. The rate of proliferation for normal mature cells equals the rate of cell death, whereas in cancer proliferation exceeds the death rate. Abnormal changes in normal cells within the body leads to the formation of a lump, called a tumor. There are various kinds of cancers; all kinds of cancer cells grow, then divide and finally redivide in place of death and result in the formation of abnormal cells. Some kinds of cancer cells frequently travel to the various region of the body via blood circulation or lymph vessels (metastasis), where they start their growth and can affect the digestive circulatory and nervous system. Cancer generally forms as a solid tumor [2].

Tumor cells show a number of features which differs from normal cells:

a) They arean independent growth factor because they can secrete their own growth factor to stimulate cellular proliferation.

b) Normal cells require contact with the extracellular environment to grow whereas tumor cells are independent. 
c) Normal cells respond to the existence of other cells in culture and form a monolayer whereas tumor cells lack this characteristic and grow over or under each other.

d) Normal cells stop proliferation once they achieve a certain density but tumor cells continue to multiply [6].

Cancers are of various types like Breast cancer, Colon cancer, Lungs Cancer, Prostate cancer, etc. In the US the third most common cancer found in colorectal cancer. The colorectal tumor is also known as colon malignancy is the progression of development from the colon or rectum [7]. It is due to the abnormal growth of cells that can spread to various regions of the body. Signs and side effects may include blood in the stool, reduced weight and tiredness [8]. Only a few of colorectal diseases are hereditary all others are because of life variables. Absence of physical activity, smoking and eating regimen are few of the reasons. Dietary habits that can cause danger include red meat and in addition liquor [9].
Colorectal cancer is a disease arising from the epithelial cells lining the colon or rectum in the gastrointestinal tract, mostly due to the mutations in the Wnt signaling pathway that enhances signaling activity $[10,11,12]$. The mutations can be inherited or acquired [13]. APC gene is the mutated gene in the case of colorectal cancer, which forms the APC protein. The APC protein stops the gathering of $\beta$-catenin protein $[14,15]$. Without APC, $\beta$-catenin gathers to high levels and moves into the nucleus, binds to DNA, and finally, the transcription of proto-oncogenes is activated [16]. These genes are normally needed for stem cell renewal and differentiation, but when expressed at high levels, they can result in cancer. Molecular model for the evolution of colorectal cancer through the adenoma-carcinoma sequence showed by fig1. The mutation occurs in APC in most of the colon cancer cases, due to the of mutations in $\beta$-catenin there is an enhancement in beta-catenin that stops its own breakdown, or show mutations in various genes such as NKD1, AXIN1, AXIN2 which were having the same function as APC [17].
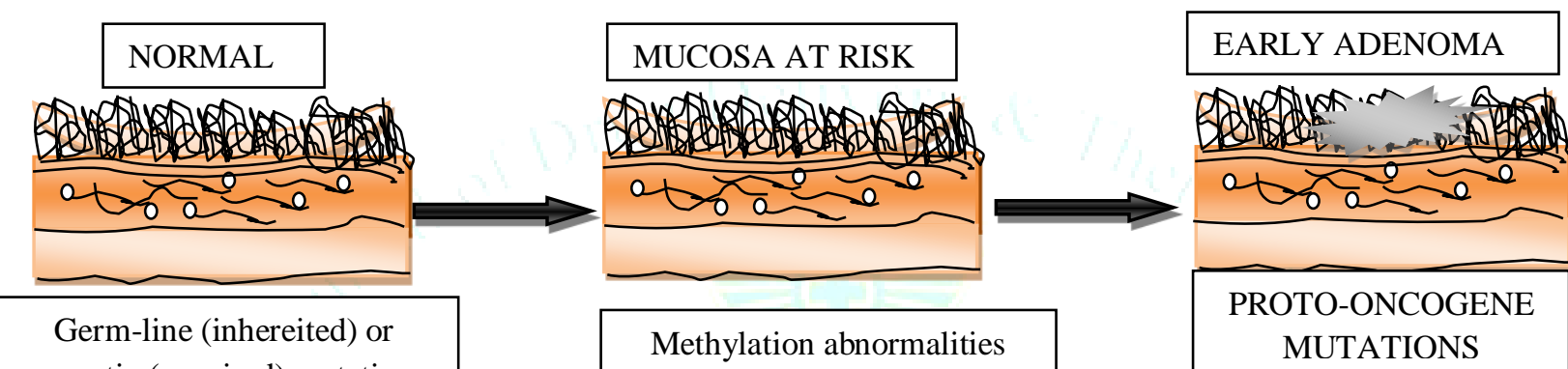

Germ-line (inhereited) or somatic (acquired) mutation ofcancer suppressor genes (first hit) [APC at 5 21]

Methylation abnormalities inactivation of normal alleles (second hit) [APC $\boldsymbol{\beta}$ CATENIN]

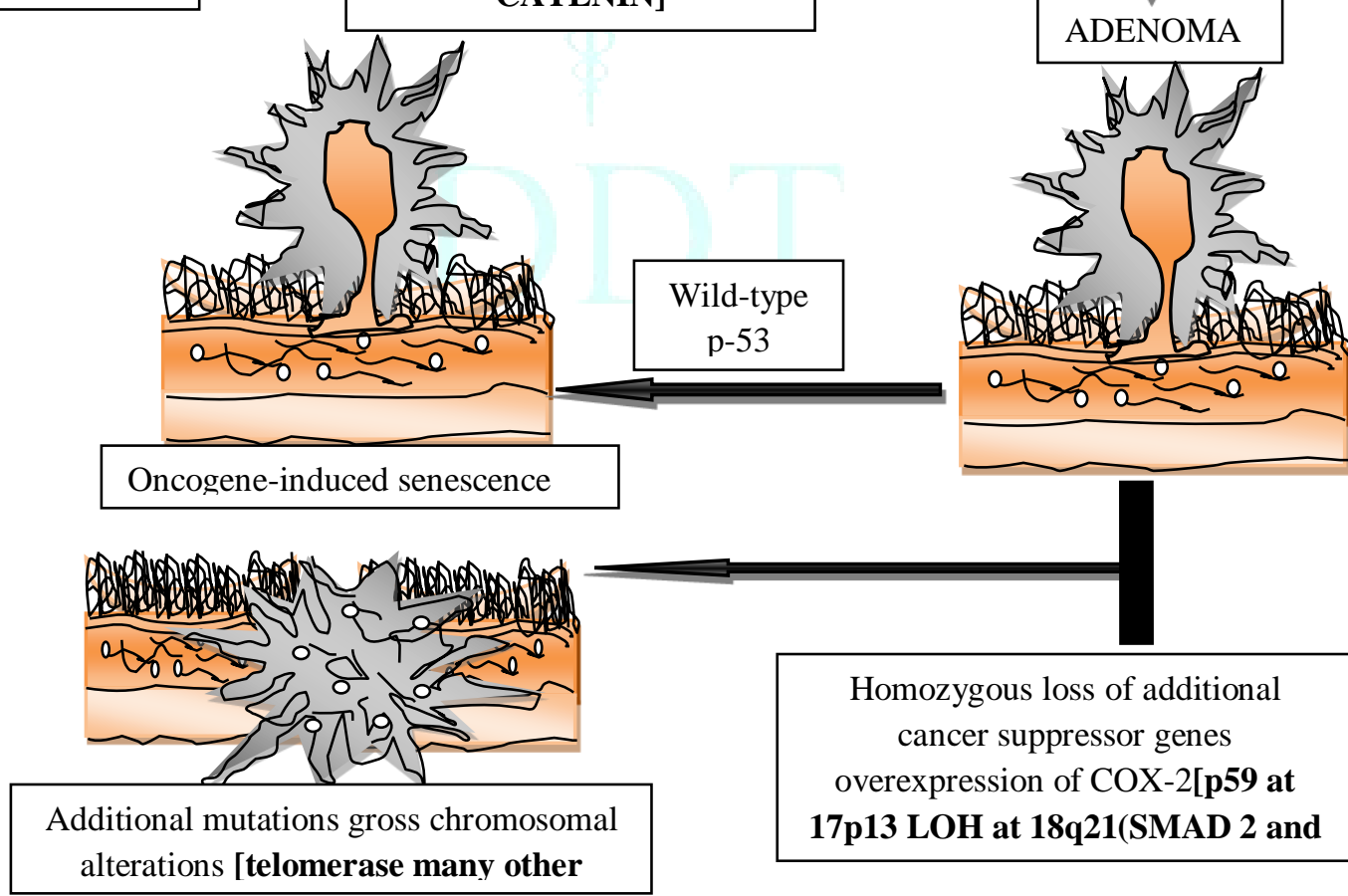

Fig 1: Molecular model for the evolution of colorectal cancer through the adenoma-carcinoma sequence. 


\subsection{Colon Cancer}

Globally, colorectal cancer (CRC) is the second most common cancer in women $(614,000$ cases per year) and the third most common in men $(746,000$ cases per year). The incidence ratesare much higher in developed countries $(737$, 000 cases per year) than in less developed ones $(624,000$ cases per year). Incidence is much more in men than women and it significantly increases with age; median age at diagnosis is about 70 years in developed countries [18]. Colorectal cancer (CRC) is the third most common type of cancer worldwide and a leading cause of cancer death During the development of colorectal adenocarcinomas there occur sequential genetic and epigenetic mutations in specific oncogenes $[19,20]$ in epithelial cells from gastrointestinal tract resulting in the start of CRC onset, its progression and metastasis [21]. Early diagnosis and better knowledge of the molecular basis of its onset and progression are very important in the treatment of CRC. This review gives an idea about managing and diagnosis of CRC [22]. CRCs occur because of various mechanisms combination, including microsatellite instability (MSI), chromosomal instability (CIN) and CpG island methylator phenotype (CIMP), According to Fearon [23], the classical CIN pathway starts with the acquiring mutations in the adenomatous polyposis coli $(A P C)$, which results in the mutational activation of oncogene KRAS and also the tumor inactivation suppressor gene, TP53. Aneuploidy and deprivation of heterozygosity ( $\mathrm{LOH}$ ) are the major players in CIN tumors, which not only constitute the sporadic tumors (85\%) but also involve familial adenomatous polyposis cases associated with germline mutations in the $A P C$ gene [24] The CIMP pathway is identified by the promoter hypermethylation of different tumor suppressor genes, like MGMT and MLH1. This hypermethylation includes the
$B R A F$ mutation and unstable microsatellite [25]. The MSI pathway includes the deactivation of genetic modifications in little repeated sequences. This startup takes place in CRCs in DNA mismatch repair (MMR) genes. Also, the hypermethylation of the MMR genes may result in MSI. This mechanism is related to the CIMP pathway [26]. MSI tumors are related to proximal colon and poor differentiation but good prognosis [27]. Three mechanisms often overlap in CRC $[23,28,29]$.

\subsubsection{Molecular basis of CRC}

During the growth of colorectal adenocarcinoma, epithelial cells from gastrointestinal trait obtain sequential genetic and epigenetic mutations in particular tumor suppressor genes, benefitting them with profit on proliferation $[19,20]$. The normal epithelium will form the hyperproliferative mucosa and eventually forms a benign adenoma that results in carcinoma and metastasis in around 10 years[21].

Sporadic colorectal cancers (CRC), due to somatic mutations, makes about $70 \%$ of all CRCs. Familial CRC accounts for around $10-30 \%$ cases whereas hereditary diseases are about $5-7 \%$ [30]. Single-nucleotide polymorphisms (SNPs) in oncogene are cause for the familial types of the disease, while hereditary CRC is caused by the inactivating mutations in the same genes [31,32]. The main hereditary CRC syndrome includes adenomatous polyposis syndrome and hereditary nonpolyposis colorectal cancer (HNPCC) [33].

\subsubsection{Hereditary CRC and molecular diagnosis}

Hereditary CRCs accounts for around $7-10 \%$ of CRC and it comprises of HNPCC, adenomatous which includes FAP and MAP and hamartomatous which comprises of PJS, JPS, PHTS polyposis syndromes [31]. The genes whose modifications are present in their onset are now well known in Table 1.

Table 1. List of gene mutations in hereditary CRC.

\begin{tabular}{|l|l|l|}
\hline Syndrome & Gene & Hereditary \\
\hline Hereditary non-polyposis colorectal cancer (HNPCC) & MLH1, MSH2, MSH6, MLH3 and PMS2 & Dominant \\
\hline Turcot Syndrome (TS) & MMR or APC & $\begin{array}{l}\text { Dominant or } \\
\text { Recessive }\end{array}$ \\
\hline Familial Adenomatous Polyposis (FAP) & APC gene & Dominant \\
\hline MUTYH-associated polyposis (MAP) & MUTYH & Recessive \\
\hline Peutz-Jeghers syndrome (PJS) & STK11/LKB1 & Dominant \\
\hline PTEN hamartoma tumors syndrome (PHTS) & PTEN & Dominant \\
\hline Juvenile polyposis syndrome (JPS) & SMAD4-BMPR1A & Dominant \\
\hline Polymerase Proofreading-Associated Polyposis (PPAP) & POLD1-POLE & Dominant \\
\hline
\end{tabular}

\subsection{Cancer Therapy}

There is no permanent treatment for cancer but palliative treatments are available. There are many drugs present in the market which have the potential to act against cancer. Most of the compounds possess anticancer activity but also have many side effects. Cancer can be treated by:
a) Surgery
b) Chemotherapy
c) Radiation therapy
d) Immunotherapy
e) Monoclonal antibody

\subsubsection{Chemotherapy:}

The term chemotherapy includes the utilization of a huge range of drugs for the management of cancer. Their drugs generally show their action by killing dividing cells or modify their growth. More and more cells are produced, and they start to occupy a great amount of space until they occupy the space previously inhabited by useful cells. Chemotherapy drugs obstruct the division and reproduction of cancer cells. A drug can be used alone or the combination of drugs can be used. They can be given directly into the bloodstream, to attack cancer cells present in the body, or they can be targeted to particular cancer regions.

Chemotherapy drugs can:

- Dame the mitosis process, or stop cell division.

- Target the substances needed for the growth of cancer cells.

- Apoptosis.

- $\quad$ Prevent the growth of new blood vessels that supply a tumor in order to starve it. 
Instead of causing the cells to starve, studies have shown that preventing the blood flow may increase the cells ability to stop treatment and lead to metastasis. They say it could be effective in stopping the cancer cells from opposing the treatment as they target the proteins that are deployed by cancer to enhance resistance and cause metastasis. Chemotherapy drugs can be categorized into different types based on the various factors such as their working mechanism, chemical structure, and the relationship they have with others. Chemotherapeutic agents can be divided on the basis of the phase of the cell cycle in which they are active.

\subsubsection{Cell cycle-specific and non-specific agents:}

Substances that are nonspecific shows a linear doseresponse curve; which means that the more the dose of the drug, more is the number of cells that are killed. However, cell cycle phase-specific drug has a plateau with respect to cell-damaging ability, and cell damage will not increase with further increase in drug dosage.

\subsection{Cell cycle-specific agents}

\section{- S phase-dependent:}

Antimetabolites: Capecitabine, Cytarabine, Doxorubicin, Fluorouracil, Floxuridine, Hydroxyurea, Mercaptopurine, Methotrexate, Prednisone.

\section{- M phase dependent:}

Vinca alkaloids: Vincristine, Vinblastine, Vinorelbine.

Podophyllotoxin: Etoposide, Teniposide.

Taxanes: Docetaxel, Paclitaxel.

\section{- G2 phase-dependent:}

Bleomycin, Irinotecan, Mitoxantrone, Topotecan.

\section{- $G_{1}$ phase-dependent:}

Aspariginase, Corticosteroids.

\subsection{Cell cycle non-specific agents}

Alkylating agents

Antibiotics

Cisplatin

\section{Nitrosoureas}

\subsubsection{Combination Chemotherapy:}

Combination chemotherapy means the utilization of more than one chemotherapy medication at a time to treat cancer. In the past, cancer was often treated with a single drug, but current treatments for many types of cancer use a combination of two or more different drugs simultaneously. It is now said to be the standard of care, especially in cancer treatment, since it is a rationale strategy to increase response and tolerability and to decrease resistance.

Combination chemotherapy helps to get the three major aims which cannot be attained with single-agent therapy:

- It damages the cell in the range of toxicity tolerated by the host.

- It gives the wide range for coverage of resistant cell lines in a heterogeneous tumor population; and

- It stops or reduces the growth of new drug-resistant cell lines.

\subsubsection{Selection of drug for combination chemotherapy}

The following principles have been accepted to help drug selection in combination regimens:

- Drugs which are active as single agents should be selected for combinations. Preferably, a drug that induces remissions should be taken.

- Drugs whose mechanisms of action differ should be combined in order to allow for additive or synergistic effects on the tumor.

- Drugs with differing dose-limiting toxicities should be combined to allow each drug to be given at full or nearly full therapeutic doses.

- Drugs should be taken at regular intervals.

- Drugs with different patterns of resistance should be combined to minimize cross-resistance.

If given at early stages, chemotherapy can result in complete treatment, making the side effects tolerable for many patients. A plan is made up that tells about the treatment sessions.

On the basis of the type of cancer, the patient may take chemotherapy orally, or intravenously, injected into the vein or elsewhere.

Orally: Tablets can be taken. The drug may also be in capsule or liquid form. The dose must be taken exactly when specified.

Intravenous chemotherapy: This can be taken directly into a vein with the help of the needle or delivered through an intravenous infusion. The drugs can also be given:

- as an injection in a muscle in the arm, thigh

- intrathecally which is injected into the in the layers of tissue that cover the brain and spinal cord

- $\quad$ as an intraperitoneal (IP) injection, directly delivered where the intestines, stomach, and liver are present

- $\quad$ intra-arterially (IA), injected into the artery that leads to cancer.

\subsection{Targeted Drug Delivery}

The whole idea targeted drugs go back to the year 1906 when Ehrlich [34] first suggested the 'magic bullet'. The permanence of this idea is a strong sign of its appeal, but the 'magic bullet' is still a challenge to implement in the clinic. The problem is with three things; first thing is finding the target for a specific disease state; to find a drug that efficiently treats this disease; and discovering an idea of taking the stable form of the drug while avoiding the immunogenic and nonspecific interactions that efficiently clear foreign material present in the body [35].

Targeted drug delivery includes giving medication to a patient in such a way that it enhances the amount of the medication in a few parts of the body in comparison to others. Targeted drug delivery includes concentrating the medication in the tissues of interest while decreasing the relative concentration of the medication in the other tissues. The drug is administered in such a manner that the drug is only active in the targeted area of the body and then the drug is released over in a controlled manner e.g., colon targeted drug. This enhances efficacy and decreases side effects. It is very hard for a drug molecule to reach its endpoint in the complicated cellular network of an individual. Targeted delivery of drugs helps the drug 
molecule to reach preferably to the required region. The benefit of using this method includes a decrease in dose \& side effect of the drug. Research associated with the development of targeted drug delivery system is nowadays highly favored in the pharmaceutical field [36].

\subsubsection{Types of Targeted Drug Delivery System:}

Targeting drug to a particular region not only enhances the therapeutic efficacy of drugs also it aims to reduce the toxicity related with the drug so that the lower doses of the drug can be used. Two approaches are used widely for drug targeting [37,38,39]. Active and passive targeted drug delivery is diagrammatically showed in fig2.

\subsubsection{Passive targeting}

It means drug or drug carrier system gathered at a particular region such as anti-cancerous drug whose explanation may be credited to pharmacological or physicochemical factors of the disease [40].

\subsubsection{Active targeting}

It includes specific ligand-receptor type interaction for intracellular localization which results after the extravasations and blood circulation [40].

1) First-order targeting refers to the confined distribution of the drug carrier systems to the capillary bed of a fixed organ, tissue.

2) Second-order targeting means selective delivery of drugs to particular cell types such as tumor cells and not to the normal cells.

3) Third-order targeting includes drug delivery particularly to the intracellular region of targeted cells [38].

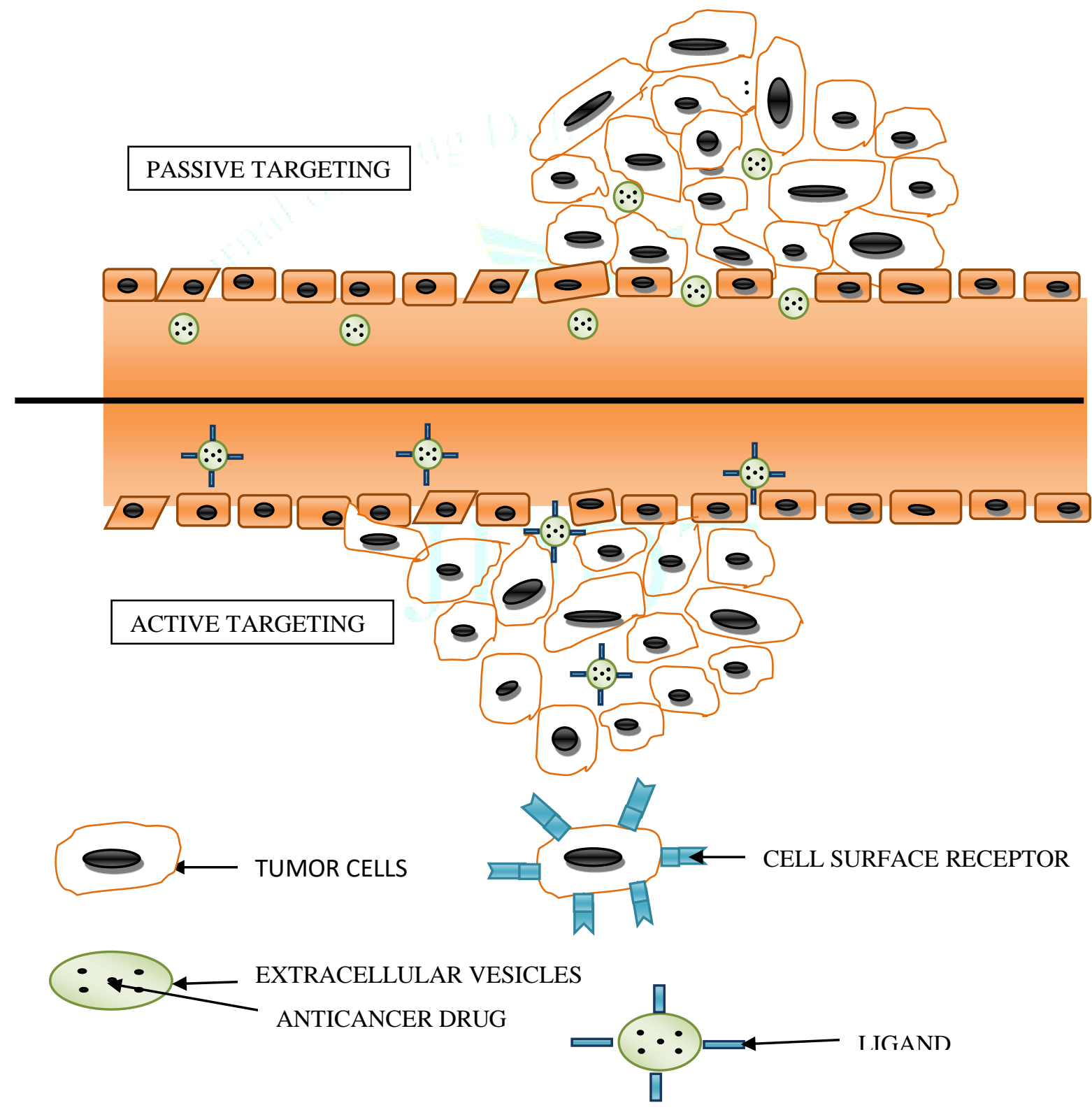

Fig 2: Active and passive targeted drug delivery. 


\subsection{Targeted Dosage Form Benefits against Conventional Dosage Form}

Chemotherapy is a type of treatment that also shows adverse effects. As the drugs often target healthy cells with cancerous cells.

- The conventional dosage forms release the drug immediately and it results in the variation of drug level in blood.

- Therefore to conserve the drug amount within therapeutic effective range, need for novel drug delivery system is there.

- It provides optimum dose in the right location at the right time.

- $\quad$ Systematic usage of expensive drugs and the excipients and decrease in production cost.

- Improved comfort, better therapy and increased standard of living.

- Reduction in dosing frequency.

- The decrease in the rate of rising of drug concentration in blood.

- To get a targeted drug release.

- Decreased side- effects.

- Fewer chances of missing the dose of a drug having the short half-life

- With the help of concepts and methods of sustained or controlled and targeted drug delivery systems, good and safer use of existing drugs.

- $\quad$ Targeted therapy includes specificity towards cancer cells while reducing toxicity to other cells.

- Targeted therapy made to enhance the effectiveness of chemotherapy because it aims specifically at the cancer cells' function that either:

- Allows cancer cells to continue growing and dividing.

- Helps to keep the tumor alive.

- Effectiveness of the therapy includes the targeted release of therapeutics at the diseased region while reducing the off-target side effects in the normal tissues.

- Targeted therapies give medical oncologists a batter method to personalize cancer treatment.

\section{Advantages of targeted therapy include:}

○ Lesser side effects

- Better effectiveness

- Better quality of life

\subsection{Colon Targeting}

The colon is a site where both local and systemic delivery of drugs can take place. Local delivery helps to treat IBD topically. The treatment can be made productive if the drugs can be targeted directly into the colon, causing a decrease in the systemic side effects.

Targeted drug delivery is needed for local treatment of a variety of bowel diseases [41,42]. The colon-specific drug delivery system (CDDS) should protect the drug i.e. the drug should only be released and absorbed once the system reaches the colon.

The colon is a good absorption site for peptides and protein drugs for various reasons

(i) less diversity and intensity of digestive enzymes,

(ii) Proteolytic activity of colon mucosa is lesser than in the small intestine,

Thus CDDS save peptide drugs from hydrolysis, and enzymatic degradation in duodenum and jejunum, and finally release the drug into ileum or colon which results in more systemic bioavailability [43] and at last, as the colon has a long residence time of about 5 days and is greatly responsive to enhancers of absorption [44].

Possible routes for colon targeting:

I. Oral route

II. Rectal route

The oral route is the preferred route [45]. Oral administration of various dosage forms is the most common type of administration due to good patient compliance and flexibility [46]. Rectal administration provides the shortest route for targeting drugs to the colon. Using the rectal route to reach to the proximal part of the colon is not easy. Delivering the medication through the rectal route can also be uncomfortable [47]. Dosage form for intrarectal administration includes solutions, foam, and suppositories. The intrarectal route is used for systemic dosing and for the topically active drug to the large intestine.

\subsubsection{Criteria for Selection of Drug for CDDS:}

The best Candidates for CDDS are drugs which show poor absorption from the stomach or intestine including peptides. The drugs used in the treatment of IBD, ulcerative colitis, diarrhea, and colon cancer are good for local colon delivery [48]. The criteria for the selection of drugs for CDDS are summarized in Table 2 . 
Table 2: Criteria for selection of drugs for CDDS [49,50,51]

\begin{tabular}{|l|l|l|l|}
\hline Criteria & Pharmacological class & Non-peptide drugs & Peptide drugs \\
\hline $\begin{array}{l}\text { Drugs used for local effects in } \\
\text { colon against GIT diseases }\end{array}$ & Anti-inflammatory drugs & $\begin{array}{l}\text { Oxyprenolol, Metoprolol, } \\
\text { Nifedipine }\end{array}$ & $\begin{array}{l}\text { Amylin, Antisense } \\
\text { oligonucleotide }\end{array}$ \\
\hline $\begin{array}{l}\text { Drugs poorly absorbed from } \\
\text { upper GIT }\end{array}$ & $\begin{array}{l}\text { Antihypertensive and } \\
\text { antianginal drugs }\end{array}$ & $\begin{array}{l}\text { Ibuprofen, Isosorbides, } \\
\text { Theophylline }\end{array}$ & $\begin{array}{l}\text { Cyclosporine, } \\
\text { Desmopressin }\end{array}$ \\
\hline Drugs for colon cancer & Antineoplastic drugs & Pseudoephedrine & Epoetin, Glucagon \\
\hline $\begin{array}{l}\text { Drugs that degrade in the } \\
\text { stomach and small intestine }\end{array}$ & Peptides and proteins & $\begin{array}{l}\text { Brompheniramine, } \\
\text { 5-Fluorouracil, Doxorubicin }\end{array}$ & $\begin{array}{l}\text { Gonadorelin, Insulin, } \\
\text { Interferons }\end{array}$ \\
\hline $\begin{array}{l}\text { Drugs that undergo extensive } \\
\text { first-pass metabolism }\end{array}$ & $\begin{array}{l}\text { Nitroglycerin and } \\
\text { corticosteroids }\end{array}$ & Bleomycin, Nicotine & $\begin{array}{l}\text { Protirelin, sermorelin, } \\
\text { Saloatonin }\end{array}$ \\
\hline $\begin{array}{l}\text { Drugs for targeting } \\
\text { Antiarthritic and } \\
\text { antiasthmatic drugs }\end{array}$ & $\begin{array}{l}\text { Prednisolone, hydrocortisone, } \\
\text { 5-Aminosalicylic acid }\end{array}$ & Somatropin, Urotoilitin \\
\hline
\end{tabular}

\subsubsection{Factors affecting colon targeted drug delivery [52]:}

\subsubsection{Physiological factors}

\subsection{Gastric emptying:}

Drug delivery to the colon upon oral administration depends mainly on gastric emptying and bowel transit time. Upon reaching the colon the transit time of dosage form depends on the size of the particles. Smaller particles have more transit time compared to larger particles. Diarrhea patients have shorter transit time whereas constipation patients have longer transit times.

\subsubsection{2 pH of the colon:}

The $\mathrm{pH}$ varies significantly between different regions of the GIT. For example, the $\mathrm{pH}$ of gastrointestinal contents can be as low as 1 to 2 in the stomach and rise to 7.5 in the distal small intestine [53]. The $\mathrm{pH}$ then declines from the end of the small intestine to the colon and gradually increases once again in the colon. This change in the $\mathrm{pH}$ in different parts of GIT is the basis for the development of colon targeted drug delivery systems. Coating with different polymers is done to target the drug to the site.

\subsection{Colonic microflora and enzymes:}

Growth of this microflora is controlled by the GIT contents and peristaltic movements. Relation of different microflora and enzymes of the colon are listed in table 3 with their metabolic reactions.

Table 3: Different microflora, enzymes released and action.

\begin{tabular}{|l|l|l|}
\hline Microorganism & Enzyme & Metabolic reaction \\
\hline E.coli, Bacteroids & Nitroreductase & Reduces aromatic \& heterocyclic nitro compounds \\
\hline Clostridia, Lactobacilli & Hydrogenase & Reduces carbonyl groups \& aliphatic double bonds \\
\hline Clostridia, Eubacteria & Glucosidase & Cleavage of glycosidase of alcohols \& phenols \\
\hline Eubacteria, Clostridia, Streptococci & Sulfatase & Cleavage of Osulphates \& sulfamates \\
\hline
\end{tabular}

\subsubsection{Pharmaceutical factors}

\subsection{Drug candidates:}

Due to more retention time of colon, a colon makes enhancement in the absorption of the drugs that are poorly absorbed like peptides and drugs used for the treatment of inflammatory bowel diseases, etc. are acceptable for colon targeted drug delivery system [46].

\subsection{Drug carriers:}

The selection of carrier is based on the nature of the drug and the disease for which the drug is used [46]. The various factors that affect the carrier selection include chemical nature, partition coefficient and stability, etc.

\subsection{Approaches used for Targeted Drug Delivery to Colon:}

7.1.1 Liposomes: These consists vesicles which are spherical in shape and are made up of phospholipid bilayers. They are said to be a good drug delivery system for drugs with various physicochemical properties [54]. As drug delivery, liposomes offer certain benefits like the capacity to enclose both hydrophilic and lipophilic drugs biodegradability, biocompatibility and other nontoxic properties $[55,56]$. In order to improve liposomal drug delivery to the tumor site, targeting approaches with the conjugation of ligands to the surface of liposomes have been extensively studied. There are various patterns of cell death when the cells are exposed to anticancer drugs. Many cell death related to transduction pathways are aided by the 
function of mitochondria [57]. Apoptosis plays a vital part in response to regulatory signals which can be either stress induced or can be of other type. There are two major types of pathways which lead to apoptosis : the intrinsic (mitochondrial) pathway and the extrinsic (death receptor) pathway. The mitochondrial pathway is activated by different types of stimuli like intracellular stimuli which includes DNA damage, oxidative stress and growth factor deprivation. The extrinsic pathway of apoptosis is started by the binding of death ligands such as Fas ligand and TNF- $\alpha$ to death receptors of the TNF receptor super family [58]. Reactive oxygen species (ROS) is an important parameter associated with cell death. The value of ROS may decide between necrosis and apoptosis [59]. It has been earlier seen that little or high levels of ROS manage the apoptotic and necrotic pathways, respectively [60].

The therapies based on the Fluoropyrimidine like administration of $5 \mathrm{FU}$ are the treatment approaches in metastatic CRC [61]. Because of the similarity in structure to the pyrimidine base of DNA and also it is an antimetabolite that acts via inhibiting essential processes for tumor cell proliferation such as DNA and RNA synthesis, 5FU interferes with the metabolism of nucleoside, resulting in cytotoxicity and finally cell death [62]. However, clinical applications of 5FU have certain limitations like short half-life $(20$ min)because of the fast metabolism and nonspecific drug distribution causing toxicity on the gastrointestinal tract, bone marrow cells, and other dermatological effects [63]. Therefore, various methods have been taken to enhance the delivery of $5 \mathrm{FU}$ so as to increase therapeutic index with a decrease in side effects. Encapsulation of $5 \mathrm{FU}$ in nanoparticles, such as liposomes, can lessen the clearance of the drug and decrease the associated toxicity [64]. This drug being highly catabolized (more than $80 \%$ ) through the activity of the dihydropyrimidine dehydrogenase in the liver [65]. Therefore, tumor-targeted delivery of 5-FU is an important idea for increasing the therapeutic index of this agent. Moreover, earlier studies have shown that tumortargeting properties of LCL (Long-Circulating Liposomes) could permit various cytotoxic drugs such as paclitaxel, cisplatin etc. to gather into the tissues [66] of the tumour and acted more effectively when compared to conventional chemotherapy system which is based on the free taking of the same drugs. Thus, LCL as nanovehicles for 5-FU will make a sure passive gathering in solid tumors, because of the unusual characteristics of the tumor vasculature also called as EPR (Enhanced Permeability and Retention) effect $[67,68]$. The LCL encapsulated 5-FU (LCL-5-FU) can also help in reducing the drug toxicity on healthy tissues. The combination of LCL-5-FU with LCL containing PLP (LCL-PLP) has inhibitory effects in colon carcinoma in vivo [69] caused by tumor angiogenesis suppression [70] and can help in the improvement of CRC treatment. To compare the antitumor activity of combined liposomal drug therapy based on simultaneous administration of $20 \mathrm{mg} / \mathrm{kg}$ LCL-PLP and 1.2 $\mathrm{mg} / \mathrm{kg}$ LCL-5-FU with that induced by liposomal monotherapy (either $20 \mathrm{mg} / \mathrm{kg}$ LCL-PLP or $1.2 \mathrm{mg} / \mathrm{kg}$ LCL-5$\mathrm{FU}$ ) on the growth of $\mathrm{C} 26$ colon carcinoma in vivo, mice were injected i.v. when tumor volumes were about $200 \mathrm{~mm}^{3}$ (at day 8) and at day 11 after tumor induction. The same dosing schedule and treatment schemes were employed when the drugs were administered as free forms. The study of Laura P. et al; showed that the growth of C26 colon carcinoma was affected fairly when LCL-5-FU was given (by 53\%, $P<0.01$ ) to strongly when LCL-PLP treatment was done (by 70\%) when compared to control tumors (PBS-/LCL-treated groups) growth according to tumor volumes measurements at scarification day [71].
Eskandar M., Mohsen R., et al; found that 5FU entrapment efficiency can be increased by increasing the number of phospholipids. So if we raise the number of phospholipids, liposomes came out to be more rigid with the capacity to keep more drugs [72]. The cytotoxicity of 5FU, liposomal 5FU, and Tf-liposomal 5FU was checked by MTT assay which is based on the capacity of succinic dehydrogenase enzyme of living cell to changing the color from yellow to dark purple [73]. HT-29 cells and fibroblast cells were taken as colon cancer cell lines and normall cells respectively to check whether targeted liposome has a cytotoxic effect on normal cells. The IC50 values for $5 \mathrm{FU}$, liposomal $5 \mathrm{FU}$, and Tfliposomal 5FU were $66.069,58.88$ and $31.62 \mu \mathrm{m}$, respectively. Also, see that no major difference was seen in the cytotoxicity of 5FU and liposomal 5FU that might be because of the internalization of nontargeted liposome inside the cells. This finding showed that targeted liposomal formulations with $\mathrm{Tf}$ altered the cellular uptake of the liposomes but also caused the better gaining of therapeutic effect with a decrease in the dose of 5FU. This finding confirms previous research of Sun et al and Zhang et al and Singh et al. Furthermore, Tf-liposomal 5FU induced apoptosis in cancer cells by lower production of ROS, decreased $\Delta \Psi \mathrm{m}$ and higher release of cytochrome c. It is concluded that $\mathrm{Tf}$ targeted liposomes would provide a promising therapeutic approach for cancer. The $\Delta \Psi \mathrm{m}$ (mitochondrial membrane potential) of HT-29 cells treated with the free drug and Tf-liposome 5FU was $0.18 \%$ and $6.36 \%$, respectively.

Statins- The cholesterol-lowering agents can be utilized as anticancer drugs, because of the uppressive action on the making of isoprenoids, products of mevalonate pathway responsible for the posttranslational alteration of a series of $G$ protein associated with the cancer cell proliferation $[74,75]$. The study was done to investigate whether colon carcinoma - specific delivery of SIM by utilizing long circulating liposomes (LCL) might be a solution for the need of high doses of this statin to obtain antitumor action while decreasing the side effects on healthy tissue. Passive tumor targeting of SIM was checked by the long-circulating ability of PEG coated liposomes. SIM-LCL with PEG coating because of EPR effect gathered in malignant tissue [76]. The maximum antitumor activity was obtained at a dose of 5 $\mathrm{mg} / \mathrm{kg}$. Tumor volumes were decreased with more than $70 \%$ at this dose and the slowing down of tumor growth at day 16 after tumor induction was around $62 \%$ when checked with the growth of control group. $5 \mathrm{mg} / \mathrm{kg}$ LCL-SIM and the same dose of free SIM on c26 colon carcinoma-bearing mice, treatments were given. Volume doubling time (DT) of tumor established the inhibitory action of LCL-SIM on tumor growth since DT for c26 tumors that obtained the liposomal treatment was about 2 times longer than DT of tumors from free SIM-treated group or control group [77].

Standard cytotoxic agents for CRC are 5FU, often taken together with irinotecan and oxaliplatin [78]. In patients with the advanced disease, almost all patients still develop resistance to treatment and succumb to tumor growth. Targeted antibodies are regularly used in treating mCRC, including agents that target vascular endothelial growth factor (VEGF) and its receptor (VEGFR) [79]. Targeting of VEGF pathways in CRC is designed to reduce tumor blood supply by disrupting tumor vessels, and has had some success in the clinic [80]. One such therapy is bevacizumab, a VEGF-targeted monoclonal antibody, which has been approved for CRC patients in combination with various chemotherapy regimens. Most of the therapeutic options in CRC have the problem of resistance in the clinic because of the to the heterogeneous nature of tumors of the colon [81]. 
Clinical trials using LP for CRC treatment focus mainly on the delivery of the well-characterized drug, including irinotecan and its metabolites, doxorubicin. LP deposition in solid tumors is heavily influenced by EPR, making the state of tumor blood vessels a key factor in delivery. Short-term bev resulted in significantly smaller vessel diameter compared to untreated controls. The total tissue area occupied by CD34+ vessels in treated tumors was $3.8 \% \pm 1.5 \%$ compared to $5.7 \% \pm 1.7 \%$ in control tumors [82].

\subsubsection{Nanoparticles:}

The preparation of nanoparticles [83] is simple and these are useful in preserving the protein and peptide drugs from the chemical and enzymatic degradation in GIT resulting in an enhancement in their stability and absorption of through the intestinal epithelium. The methods include the involvement of organic solvents, heat, and agitation. The disadvantage of these methods is that the heat is causing damage to the proteins and peptide drugs [46]. Ionic gelation method is used for proteins and peptide drugs. The use of nanoparticles (NPs) in the treatment of cancer treatment works on EPR effect to tumor tissues [84]. Due to irregular leaky vasculature and damaged lymphatic drainage in the tumors, NPs can be punctured in the tumor tissue and release the drug at particular areas; as a result, to decrease the exposure to normal tissues, and reduce the side effects. NPs can be further altered by targeting ligands [85]. Antibodies, carbohydrates, peptides, folate acid (FA) and transferring are among the several ligands to target cancer cells [86].

Le et al. in 2015 prepared 5FU loaded folate targeted nanoparticles. They reported that there was no significant difference between the cytotoxicity of 5FU and 5FU loaded NPs on cancer cells. The cytotoxicity of folate targeted NPs was significantly increased compared to free drug and nontargeted NPs. The NPs having the size around 100 to $200 \mathrm{~nm}$ gathered much efficiently in solid tumors than normal tissues. They also said that folate-targeted NPs might enter inside the tumor cells by endocytosis which is mediated through folate receptor [87]. They have seen that the addition of free folic acid to the folate-free culture medium of CT26 cells, cell viability was enhanced to $51.98 \pm 6.3 \%$. These results showed that the free folic acid stopped the FRdependent binding and uptake of NPs, which showed that the folic acid targeted NPs were up taken [88]. Lv et al. showed that capsaicin loaded folate-targeted NPs showed a remarkably higher toxic effect compared to non-targeted NPs. They showed that the anticancer action of drug loadedtargeted NPs are because of the cellular uptake of NPs via FRs-mediated endocytosis pathway [89].

Selenium nanoparticles cause the chemo-sensitivity of 5fluorouracil (FU)-encapsulated poly (D, L-lactide-coglycolide) nanoparticles (nano-FU) in colon cancer and breast cancer cell lines. Nano-Se and nanoFU were made and checked, then used individually or in combination upon MCF7, MDA-MB-231, HCT 116, and Caco-2 cancerous cell lines. Cytotoxicity, cellular glucose uptake, and apoptosis, as well as malondialdehyde (MDA), nitric oxide (NO), and zinc $(\mathrm{Zn})$ levels were investigated upon the different treatments. The results revealed a dose-dependent decrease in cell viability of MCF7 and MDA-MB-231 cancerous cell lines, with a little bit increase in cytotoxicity when comparing MCF7 and Caco-2 with MDA-MB-231 and HCT 116 lines. Furthermore, $\mathrm{FU}$ and nano-FU had the highest cytotoxic effects at $50 \mu \mathrm{m}$ with 80.9 and $78.8 \%$ of MDA-MB-231 cell viabilities, respectively, while 62.0 and $60.3 \%$ of MCF7 cell viabilities, respectively, at $24 \mathrm{~h}$. On the other hand, FU and nano-FU had the highest cytotoxic effects at $50 \mu \mathrm{m}$ with 77.7 and $83.0 \%$ of
HCT 116 cell viabilities, respectively, while 69.1 and $66.9 \%$ of Caco- 2 cell viabilities, respectively, at $24 \mathrm{~h}$ [90].

The capecitabine nanoparticles (CB-SLNs) were prepared by the microemulsion method. From the results, $\mathrm{C}_{\max }$ and $\mathrm{t}_{\max }$ of the SLN and suspension formulation were found to be $6.81 \pm 0.63$ and $3.19 \pm 0.47 \mu \mathrm{g} / \mathrm{mL} ; 2 \pm 0.0$ and $1 \pm 0.0 \mathrm{~h}$, respectively.

The hyaluronic acid (HA)-conjugated mesoporous silica nanoparticles(MSN) loaded with 5-fluorouracil (5-FU) was prepared to increase the anticancer efficacy in colon cancers. The presence of HA on the surface of nanoparticles targeted the CD44 receptors overexpressed in the colon cancer cells. HA/FMSN resulted in higher around $43 \%$ of cells in the starting of the apoptosis phase and $55 \%$ of cells in late apoptosis phase showing the great anticancer effect of HA/ FMSN. HA/FMSN showed a major decrease in the tumor burden when the comparison was done with any of that of the group. HA/FMSN was 3-fold more effective than free drug and 2-fold more effective than -FU loaded mesoporous silica nanoparticles (FMSN).

\subsubsection{Monoclonal antibodies:}

We have recently demonstrated that the atypical cadherin FAT1 is a particular marker of CRC and that the FAT1specific monoclonal antibody mAb198.3 may provide a new therapeutic opportunity for CRC, being nicely internalized by cancer cells and decreasing cancer growth in colon cancer xenograft models. In this study, we checked the therapeutic effect of mAb198.3 utilizing the two drug delivery systems (DDS) for enhancing the targeted management of CRC. The mAb198.3 can directly attach to super-paramagnetic nanoparticles (spmNPs) or embedded into erythrocytebased carriers, named Erythro-Magneto-Hemagglutinin Virosomes (EMHVs) to produce two different novel mAb198.3 formulations. Both DDS have magnetic properties and were harbored in the target tumor region with the help of an external permanent magnet. mAb198.3 and its isotypematched antigen-unrelated control (isomAb) were crosslinked l of spmNP [90]. A final concentration of $1.2 \mu \mathrm{g}$ in $200 \mu \mathrm{l}$ of spmNP suspension was achieved for either of the two antibodies. The mAb198.3-spmNP formulation was compared to free mAb198.3 in terms of ability to bind the FAT1-positive HCT15 colon cancer cell line, by using flow cytometry. mAb198.3 (300 $\mathrm{\mu g} /$ dose) induced a significant anti-tumor effect, expressed as normalized tumor mass volume, starting from the 5 th injection with respect both to equivalent free isomAb and control (two ways ANOVA RM p< 0.003) although mAb198.3-spmNP formulation employed an antibody dosage at least 300 fold lower than the free mAb198.3 treatment. These results indicate an improvement in terms of pharmacodynamics of mAb 198.3 formulated with the magnetic nanoparticle carrier.

\subsubsection{Prodrug:}

It is the inactive type of an active parent drug that goes through a transformation which is mainly enzymatic to release the active drug. The different carriers used for prodrug linkages are described in table4. Gal-Dox was synthesized by following a series of steps in good to excellent yield [91]. Administration of Gal-Dox showed remarkable tumor growth inhibition (53.1\%) compared to free Dox treatment (34.9\%, see Fig. 5D). Although Dox has been known to have several adverse effects such as cardiotoxicity, no significant in vivo toxicities were observed during this study.

The xylan-5-fluorouracil-1-acetic acid (Xyl-5-FUAC) conjugates as colon-specific prodrugs were synthesized. The 
chemical stability of the conjugates was performed in acidic (pH 1.2) and basic buffers ( $\mathrm{pH} 7.4$ ), which showed their stability in the upper gastrointestinal tract. The in-vitro drug release profiles of the conjugates were studied in the presence of rat's gastrointestinal contents [92]. The results showed that the low amounts of drug 3-4\% and 5-7\% were released in gastric and small intestine contents respectively, while $53-61 \%$ of the drug was released in the caecum and colonic contents. The cytotoxicity studies of the conjugates were checked on human colorectal cancer cell line (HTC-15 and HT-29), and it was seen that the conjugates were more cytotoxic when compared to the free drug. Finally, the results showed that the Xyl-5-FUAC conjugates can be used for colon-specific drug delivery in the treatment of colonic cancer with decreased side effects [93]. In this IC50 of 5-FU against HT-29 cells (i.e. $4.545(\mu \mathrm{g} / \mathrm{ml})$ declined drastically to a value of $1.818(\mu \mathrm{g} / \mathrm{ml})$ and $1.454(\mu \mathrm{g} / \mathrm{ml})$ in case of Xyl5FUAC (1:1) and Xyl-5-FUAC (1:2) respectively. Similarly in case of HCT-15 also 5-FU, IC50value declined from 2.54 $\mu \mathrm{g} / \mathrm{ml}$ to $2.09 \mu \mathrm{g} / \mathrm{ml}$ and $1.727 \mu \mathrm{g} / \mathrm{ml}$ for Xyl-5-FUAC (1:1) and Xyl-5FUAC (1:2) respectively.

Table 4: Examples of Prodrug system for CDDS

\begin{tabular}{|l|l|l|}
\hline Drug & Carrier & Linkage hydrolyzed \\
\hline 5-ASA & Azo conjugates & Azo linkage \\
\hline Dexamethasone & Saccharide carriers & Glycosidic linkage \\
\hline Prednisolone, hydrocortisone, fludrocortisones & Glucose, galactose & Glycosidic linkage \\
\hline Salicylic acid & Amino acid conjugates, glycine & Amide linkage \\
\hline
\end{tabular}

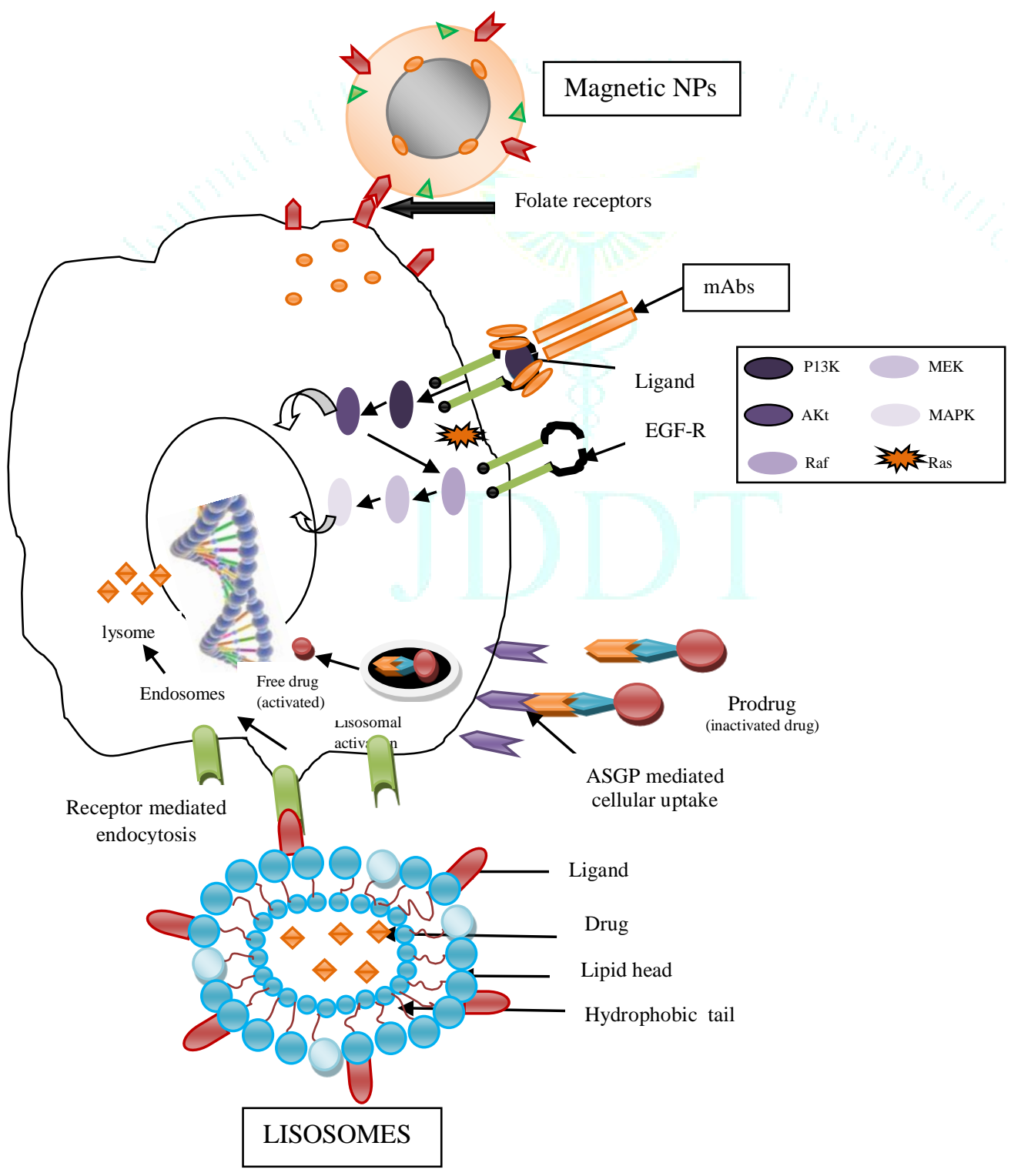

Figure 3: Mechanism of internalization of different targeted drug carries. 


\section{REFERENCES}

1. Kapur BN. The fruits of long endeavors-200 years of oncology. Medical journal, Armed Forces India. 2014;70(2):95.

2. Sudhakar A. History of cancer, ancient and modern treatment methods. Journal of cancer science \& therapy. 2009;1(2):1.

3. Bonica JJ, Ekstrom JL. SYSTEMIC OPIOIDS FOR THE MANAGEMENT OF CANCER PAIN-AN UPDATED REVIEW. Advances in pain research and therapy. 1990;14:425-46.

4. Rao DN, Ganesh B. Estimate of cancer incidence in India in 1991 Indian journal of cancer. 1998;35(1):10-8.

5. Lodish H, Berk A, Zipursky SL, Matsudaira P, Baltimore D, Darnell J. Molecular cell biology 4th edition. National Center for Biotechnology Information, Bookshelf. 2000.

6. Macdonald F, Ford C, Casson A. Molecular biology of cancer Taylor \& Francis; 2004.

7. Agrawal D. Diagnosis and treatment of colorectal cancer: a review Journal of Drug Delivery and Therapeutics. 2012;2(3).

8. Yang IP, Tsai HL, Miao ZF, Huang CW, Kuo CH, Wu JY, Wang WM Juo SH, Wang JY. Development of a deregulating microRNA panel for the detection of early relapse in postoperative colorectal cancer patients. Journal of translational medicine. 2016;14(1):108.

9. Haggar FA, Boushey RP. Colorectal cancer epidemiology: incidence, mortality, survival, and risk factors. Clinics in colon and rectal surgery. 2009;22(4):191.

10. Kinzler KW, Vogelstein B. Colorectal tumors. In: Vogelstein B, Kinzler KW, eds. The genetic basis of human cancer. 2nd ed. New York: McGraw-Hill, 2002:583-612.

11. Fearon ER, Bommer GT. Molecular biology of colorectal cancer. In: DeVita VT Jr, Lawrence TS, Rosenberg SA, eds. DeVita, Hellman, and Rosenberg's cancer: principles \& practice of oncology. Vol. 1 Philadelphia: Lippincott Williams \& Wilkins, 2008:1218-31.

12. Goss $\mathrm{KH}$, Groden J. Biology of the adenomatous polyposis coli tumor suppressor. J Clin Oncol 2000;18:1967-79.

13. Bilbao-Sieyro C, Ramírez-Moreno R, Rodríguez-González G, Falcón O, León L, Torres S, Fernández L, Alonso S, Díaz-Chico N, Perucho M, Díaz-Chico JC. Microsatellite instability and ploidy status define three categories with distinctive prognostic impact in endometrioid endometrial cancer. Oncotarget. 2014;5(15):6206.

14. Chakravarthi S, Krishnan B, Madhavan M. Apoptosis and expression of p53 in colorectal neoplasms. Indian J Med Res. 1999;86(7):95-102.

15. Khalek FJ, Gallicano GI, Mishra L. Colon cancer stem cells Gastrointestinal cancer research: GCR. 2010(Suppl 1):S16.

16. Korinek V, Barker N, Morin PJ, et al. Constitutive transcriptional activation by a beta-catenin-Tcf complex in APC-/- colon carcinoma. Science 1997;275:1784-7

17. Markowitz SD, Bertagnolli MM. Molecular basis of colorecta cancer. New England Journal of Medicine. 2009;361(25):2449-60.

18. Tariq K, Ghias K. Colorectal cancer carcinogenesis: a review of mechanisms. Cancer biology \& medicine. 2016;13(1):120.

19. Pancione M, Remo A, Colantuoni V. Genetic and epigenetic events generate multiple pathways in colorectal cancer progression. Pathology research international. 2012;2012.

20. Ewing I, Hurley JJ, Josephides E, Millar A. The molecular genetics of colorectal cancer. Frontline gastroenterology. 2014;5(1):26-30.

21. Vogelstein B, Fearon ER, Hamilton SR, Kern SE, Preisinger AC Leppert M, Smits AM, Bos JL. Genetic alterations during colorectaltumor development. New England Journal of Medicine. 1988;319(9):525-32.

22. De Rosa M, Pace U, Rega D, Costabile V, Duraturo F, Izzo P, Delrio P. Genetics, diagnosis and management of colorectal cancer Oncology reports. 2015;34(3):1087-96.

23. Fearon ER, Vogelstein B. A genetic model for colorectal tumorigenesis. Cell. 1990;61(5):759-67.

24. Smith G, Carey FA, Beattie J, Wilkie MJ, Lightfoot TJ, Coxhead J, Garner RC, Steele RJ, Wolf CR. Mutations in APC, Kirsten-ras, and p53-alternative genetic pathways to colorectal cancer Proceedings of the National Academy of Sciences. 2002;99(14):9433-8.

25. Weisenberger DJ, Siegmund KD, Campan M, Young J, Long TI, Faasse MA, Kang GH, Widschwendter M, Weener D, Buchanan D, Koh H. CpG island methylator phenotype underlies sporadic microsatellite instability and is tightly associated with BRAF mutation in colorectal cancer. Nature genetics. 2006;38(7):787.

26. East JE, Saunders BP, Jass JR. Sporadic and syndromic hyperplastic polyps and serrated adenomas of the colon: classification, molecular genetics, natural history, and clinical management. Gastroenterology Clinics. 2008;37(1):25-46.

27. Sameer AS, Nissar S, Fatima K. Mismatch repair pathway: molecules, functions, and role in colorectal carcinogenesis. European Journal of Cancer Prevention. 2014;23(4):246-57.

28. Lynch HT, De la Chapelle A. Hereditary colorectal cancer. New England Journal of Medicine. 2003;348(10):919-32.

29. Lao VV, Grady WM. Epigenetics and colorectal cancer. Nature Reviews Gastroenterology and Hepatology. 2011;8(12):686.

30. Burt RW. Colon cancer screening. Gastroenterology. 2000;119(3):837-53.

31. Jasperson KW, Tuohy TM, Neklason DW, Burt RW. Hereditary and familial colon cancer. Gastroenterology. 2010;138(6):204458.

32. Duraturo F, Liccardo R, Cavallo A, Rosa MD, Grosso M, Izzo P. Association of low-risk MSH3 and MSH2 variant alleles with Lynch syndrome: Probability of synergistic effects. International journal of cancer. 2011;129(7):1643-50.

33. Rustgi AK. The genetics of hereditary colon cancer. Genes \& development. 2007;21(20):2525-38.

34. Ehrlich PR, Marquardt M, Dale HH. The collected papers of Paul Ehrlich: in four volumes including a complete bibliography.. 1. Histology, biochemistry and pathology. Pergamon Press; 1956.

35. Fahmy TM, Fong PM, Goyal A, Saltzman WM. Targeted for drug delivery. Materials Today. 2005;8(8):18-26.

36. Manish G, Vimukta S. Targeted drug delivery system: a review. Res J Chem Sci. 2011;1(2):135-8.

37. Gref R, Minamitake Y, Peracchia MT, Trubetskoy V, Torchilin V, Langer R. Biodegradable long-circulating polymeric nanospheres. Science. 1994;263(5153):1600-3.

38. Kannagi R, Izawa M, Koike T, Miyazaki K, Kimura N Carbohydrate-mediated cell adhesion in cancer metastasis and angiogenesis. Cancer science. 2004;95(5):377-84.

39. Muller RH, Keck CM. Challenges and solutions for the delivery of biotech drugs-a review of drug nanocrystal technology and lipid nanoparticles. Journal of biotechnology. 2004;113(1-3):151-70.

40. Rani K, Paliwal S. A review on targeted drug delivery: Its entire focus on advanced therapeutics and diagnostics. Sch. J. App. Med. Sci. 2014;2(1C):328-31.

41. Philip AK, Dabas S, Pathak K. Optimized prodrug approach: A means for achieving enhanced anti-inflammatory potential in experimentally induced colitis. Journal of drug targeting. 2009;17(3):235-41.

42. Odeku OA, Fell JT. In-vitro evaluation of khaya and albizia gums as compression coatings for drug targeting to the colon. Journal of Pharmacy and Pharmacology. 2005;57(2):163-8.

43. Chourasia MK, Jain SK. Pharmaceutical approaches to colon targeted drug delivery systems. J Pharm Pharm Sci. 2003;6(1):33-66.

44. Basit A, Bloor J. Prespectives on colonic drug delivery, Business briefing. Pharmaceutical Technology. 2003:185-90.

45. Philip AK, Philip B. Colon targeted drug delivery systems: a review on primary and novel approaches. Oman medical journal. 2010;25(2):79.

46. Sreelatha D, Brahma CK. Colon targeted drug delivery-a review on primary and novel approaches. Journal of Global Trends in Pharmaceutical Sciences. 2013;4(3):1174-83.

47. Watts PJ, Lllum L. Colonic drug delivery. Drug development and industrial pharmacy. 1997;23(9):893-913.

48. Vyas SP, Khar RK. Controlled drug delivery concepts and advances. vallabh prakashan. 2002;1:411-47.

49. Antonin KH, Rak R, Bieck PR, Preiss R, Schenker U, Hastewell J, Fox R, Mackay M. The absorption of human calcitonin from the transverse colon of man. International journal of pharmaceutics. 1996;130(1):33-9.

50. Prescott LF. Novel drug delivery and its therapeutic application. John Wiley \& Sons; 1989.

51. Mackay M, Tomlinson E. Colonic delivery of therapeutic peptides and proteins. Drugs and the pharmaceutical sciences. 1993;60:159-76.

52. Challa T, Vynala V, Allam KV. Colon specific drug delivery systems: A review on primary and novel approaches. International Journal of Pharmaceutical Sciences Review and Research. 2011;7(2):171-81. 
53. Reddy RD, Malleswari K, Prasad G, Pavani G. Colon targeted drug delivery system: a review. International Journal of Pharmaceutical Sciences and Research. 2013;4(1):42.

54. Akbarzadeh A, Rezaei-Sadabady R, Davaran S, Joo SW, Zarghami N, Hanifehpour Y, Samiei M, Kouhi M, Nejati-Koshki K. Liposome: classification, preparation, and applications. Nanoscale research letters. 2013;8(1):102.

55. Akbarzadeh A, Rezaei-Sadabady R, Davaran S, Joo SW, Zarghami N, Hanifehpour Y, Samiei M, Kouhi M, Nejati-Koshki K. Liposome: classification, preparation, and applications. Nanoscale research letters. 2013;8(1):102.

56. Pereira S, Egbu R, Jannati G. Docetaxel-loaded liposomes: The effect of lipid composition and purification on drug encapsulation and in vitro toxicity. International journal of pharmaceutics. 2016;514(1):150-9.

57. Deshpande PP, Biswas S, Torchilin VP. Current trends in the use of liposomes for tumor targeting. Nanomedicine. 2013;8(9):1509-28.

58. Su Z, Yang Z, Xu Y, Chen Y, Yu Q. Apoptosis, autophagy, necroptosis, and cancer metastasis. Molecular cancer. 2015;14(1):48.

59. Baigi MG, Brault L, Néguesque A, Beley M, El Hilali R, Gaüzère F, Bagrel D. Apoptosis/necrosis switch in two different cancer cell lines: influence of benzoquinone-and hydrogen peroxideinduced oxidative stress intensity, and glutathione. Toxicology in Vitro. 2008;22(6):1547-54

60. Higuchi M, Honda T, Proske RJ, Yeh ET. Regulation of reactive oxygen species-induced apoptosis and necrosis by caspase 3like proteases. Oncogene. 1998;17(21):2753.

61. Zhang N, Yin Y, Xu SJ, Chen WS. 5-Fluorouracil: mechanisms of resistance and reversal strategies. Molecules. 2008;13(8):155169.

62. Yadav AK, Agarwal A, Rai G, Mishra P, Jain S, Mishra AK, Agrawal $\mathrm{H}$, Agrawal GP. Development and characterization of hyaluronic acid decorated PLGA nanoparticles for delivery of 5fluorouracil. Drug delivery. 2010;17(8):561-72.

63. de Mattos AC, Altmeyer C, Tominaga TT, Khalil NM, Mainardes RM. Polymeric nanoparticles for oral delivery of 5-fluorouracil: Formulation optimization, cytotoxicity assay and pre-clinical pharmacokinetics study. European Journal of Pharmaceutical Sciences. 2018;84:83-91.

64. Sharma A, Kaur A, Jain UK, Chandra R, Madan J. Stealth recombinant human serum albumin nanoparticles conjugating 5-fluorouracil augmented drug delivery and cytotoxicity in human colon cancer, HT-29 cells. Colloids and Surfaces B: Biointerfaces. 2017;155:200-8.

65. Diasio RB, Beavers TL, Carpenter JT. Familial deficiency of dihydropyrimidine dehydrogenase. Biochemical basis for familial pyrimidinemia and severe 5-fluorouracil-induced toxicity. The Journal of clinical investigation. 1988;81(1):47-51.

66. Pillai G, Ceballos-Coronel ML. Science and technology of the emerging nanomedicines in cancer therapy: A primer for physicians and pharmacists. SAGE open medicine. 2013;1:2050312113513759.

67. Maeda H, Wu J, Sawa T, Matsumura Y, Hori K. Tumor vascular permeability and the EPR effect in macromolecular therapeutics: a review. Journal of controlled release. 2000;65(12):271-84.

68. Torchilin V. Tumor delivery of macromolecular drugs based on the EPR effect. Advanced drug delivery reviews. 2011;63(3):131-5.

69. Schiffelers RM, Fens MH, Janssen AP, Molema G, Storm G. Liposomal targeting of angiogenic vasculature. Current drug delivery. 2005;2(4):363-8

70. Sylvester B, Porfire A, Muntean DM, Vlase L, Luput L, Licarete E, Sesarman A, Alupei MC, Banciu M, Achim M, Tomuţă I. Optimization of prednisolone-loaded long-circulating liposomes via application of Quality by Design (QbD) approach. Journal of liposome research. 2018;28(1):49-61.

71. Patras L, Sylvester B, Luput L, Sesarman A, Licarete E, Porfire A Muntean D, Drotar DM, Rusu AD, Nagy AL, Catoi C. Liposomal prednisolone phosphate potentiates the antitumor activity of liposomal 5-fluorouracil in C26 murine colon carcinoma in vivo. Cancer biology \& therapy. 2017;18(8):616-26.

72. Elmeshad AN, Mortazavi SM, Mozafari MR. Formulation and characterization of nanoliposomal 5-fluorouracil for cancer nanotherapy. Journal of liposome research. 2014;24(1):1-9.
73. Waheed A, Bibi Y, Nisa S, Chaudhary FM, Sahreen S, Zia M. Inhibition of human breast and colorectal cancer cells by Viburnum foetens L. extracts in vitro. Asian Pacific journal of tropical disease. 2013;3(1):32.

74. Chan KK, Oza AM, Siu LL. The statins as anticancer agents. Clinical cancer research. 2003 Jan 1;9(1):10-9.

75. Licarete E, Sesarman A, Banciu M. Exploitation of pleiotropic actions of statins by using tumour-targeted delivery systems. Journal of microencapsulation. 2015;32(7):619-31.

76. Luput L, Licarete E, Drotar DM, Nagy AL, Sesarman A, Patras L, Rauca VF, Porfire A, Muntean D, Achim M, Tomuta I. In Vivo Double Targeting of C26 Colon Carcinoma Cells and Microenvironmental Protumor Processes Using Liposomal Simvastatin. Journal of Cancer. 2018;9(2):440.

77. Lee JK, Chan AT. Molecular prognostic and predictive markers in colorectal cancer: current status. Current colorectal cancer reports. 2011;7(2):136-44

78. Seow HF, Yip WK, Fifis $T$. Advances in targeted and immunobased therapies for colorectal cancer in the genomic era. OncoTargets and therapy. 2016;9:1899.

79. Prenen H, Vecchione L, Van Cutsem E. Role of targeted agents in metastatic colorectal cancer. Targeted oncology. 2013;8(2):8396.

80. Bijnsdorp IV, Peters GJ, Temmink OH, Fukushima M, Kruyt FA. Differential activation of cell death and autophagy results in an increased cytotoxic potential for trifluorothymidine compared to 5-fluorouracil in colon cancer cells. International journal of cancer. 2010;126(10):2457-68.

81. Blocker SJ, Douglas KA, Polin LA, Lee H, Hendriks BS, Lalo E, Chen W, Shields AF. Liposomal 64Cu-PET Imaging of Anti-VEGF Drug Effects on Liposomal Delivery to Colon Cancer Xenografts. Theranostics. 2017;7(17):4229.

82. Kothawade PD, Gangurde HH, Surawase RK, Wagh MA, Tamizharasi S. Conventional and novel approaches for colon specific drug delivery.

83. Nair L, Jagadeeshan S, Nair SA, Kumar GV. Biological evaluation of 5-fluorouracil nanoparticles for cancer chemotherapy and its dependence on the carrier, PLGA. International journal of nanomedicine. 2011;6:1685.

84. Chen Y, Liu J, Angelov B, Drechsler M, Garamus VM, WillumeitRömer R, Zou A. Baicalin loaded in folate-PEG modified liposomes for enhanced stability and tumor targeting. Colloids and Surfaces B: Biointerfaces. 2016;140:74-82.

85. Deshpande PP, Biswas S, Torchilin VP. Current trends in the use of liposomes for tumor targeting. Nanomedicine. 2013;8(9):1509-28.

86. Le VM, Wang JJ, Yuan M, Yin GF, Zheng YH, Shi WB, Lang MD, Xu LM, Liu JW. An investigation of antitumor efficiency of novel sustained and targeted 5-fluorouracil nanoparticles. European journal of medicinal chemistry. 2015;92:882-9.

87. Varshosaz J, Hassanzadeh F, Sadeghi-Aliabadi H, Firozian F. Uptake of etoposide in CT-26 cells of colorectal cancer using folate targeted dextran stearate polymeric micelles. BioMed research international. 2014;2014.

88. Moghimipour E, Rezaei M, Ramezani Z, Kouchak M, Amini M, Angali KA, Dorkoosh FA, Handali S. Folic acid-modified liposomal drug delivery strategy for tumor targeting of 5fluorouracil. European Journal of Pharmaceutical Sciences. 2018;114:166-74.

89. Abd-Rabou AA, Shalby AB, Ahmed HH. Selenium Nanoparticles Induce the Chemo-Sensitivity of Fluorouracil Nanoparticles in Breast and Colon Cancer Cells. Biological trace element research. 2018:1-2.

90. Sharma A, Kim EJ, Shi H, Lee JY, Chung BG, Kim JS. Development of a theranostic prodrug for colon cancer therapy by combining ligand-targeted delivery and enzyme-stimulated activation. Biomaterials. 2018;155:145-51.

91. Grifantini R, Taranta M, Gherardini L, Naldi I, Parri M, Grandi A Giannetti A, Tombelli S, Lucarini G, Ricotti L, Campagnoli S. Magnetically driven drug delivery systems improving targeted immunotherapy for colon-rectal cancer. Journal of Controlled Release. 2018.

92. Kumar SU, Gopinath P, Negi YS. Synthesis and bio-evaluation of xylan-5-fluorouracil-1-acetic acid conjugates as prodrugs for colon cancer treatment. Carbohydrate polymers. 2017;157:1442-50. 